\title{
Two New Species of Gyrodactylus (Monogenea: Gyrodactylidae) of Eel, Anguilla japonica, with Some Data on the Occurrence of Gyrodactylids in Greenhouse Culture at Yoshida, Shizuoka Prefecture, Japan
}

\author{
Kazuo OGAWA*1 and Masataka HIoKI*2 \\ * Department of Fisheries, Faculty of Agriculture, the \\ University of Tokyo, Yayoi, Bunkyo-ku, Tokyo, 113 Japan \\ *2Laboratory of Maruhai-Yoshida Eel Farmers' Cooperative \\ Association, Kataoka, Yoshida-cho, Haibara-gun, \\ Shizuoka Pref., 421-03 Japan
}

(Received January 6, 1986)

\begin{abstract}
Descriptions are given of two new species of Gyrodactylus collected from the body surface of eel, Anguilla japonica, in greenhouse ponds at Yoshida, Shizuoka Pref. G. egusai sp. nov. differs from most simuilar G. varicorhini ERGENS et IBRAGIMOv, 1976 in considerably smaller hamuli and marginal hook proper. $G$. joi sp. nov. is distinguished from most related G. anudarini ERGENS et DULmaA, 1968 in the shape of the marginal hook proper.

Long term changes in the occurrence of Gyrodactylus nipponensis on the gill fillaments and G. egusai and G. joi on the body surface were studied during 1980-1985. Gyrodactylus on the body surface was more frequently found than $G$. nipponensis throughout the study period. Gyrodactylids on both sites were less frequently observed in 1983-1985 than in 1980-1982, and also in summer than in the other seasons. Possible reasons for the seasonal and yearly fluctuations in Gyrodactylus populations are briefly discussed.
\end{abstract}

Yoshida area, Shizuoka Pref. is one of the centers of eel culture industry in Japan, with a total of about 100 ha ponds and annual production of well over 3,000 tons in 1984 . Recently, gyrodactylids have been collected from the body surface of eel, Anguilla japonica, cultured there. A parasitological investigation has revealed that the gyrodactylids on the body surface are different from Gyrodactylus nipponensis Ogawa et EgusA, 1978, the only known gyrodactylid from the host, and, therefore, represent two new species.

The junior author, a member of the local eel farmers' cooperative association, routinely conducts diagnositical work on health conditions of cultured eel. The work includes check for parasites on the gills and body surface. The record of the results for recent six years had been kept there, which enabled us to study the seasonal and yearly flucturations in the occurrence of the gyrodactylids in the area.

\section{Materials and Methods}

Gyrodactylus specimens were collected from scrapings of the body surface of eel cultured at Yoshida, Shizuoka Pref. They were fixed in ammonium picrate-glycerin, dehydrated in alcohol, and mounted in Canada balsam, or fixed in $10 \%$ formalin and mounted in glycerol-gelatine. A phase-contrast microscope was used for measurement and drawing of the type specimens with the aid of a camera lucida. Measurements are given in $\mu \mathrm{m}$ unless otherwise stated.

Long term changes in the occurrence of eel gyrodactylids were investigated based on the results of diagnostical work carried out by the junior autheor. A total of 11,152 samples (62-301 per month) of eel from elvers to marketable size in greenhouse ponds were diagnosed during 19801985 , each sample usually consisting of five specimens of eel (rarely less than five). For diagnoses of parasitoses, a gill on either side of body and 
scrapings of the body surface of all the five eel were examined under a microscope $(40 \times)$. Samples, in which at least one out of five eel was infected with gyrodactylids, were recorded as positive about the parasite; the percentage occurrence in this paper does not represent the prevalence of infection in the true sense of the term.

\section{Results}

Description of the new species

Gyrodactylus egusai sp. nov.

(Figs. 1-4)

Host and habitat: On the body surface of Anguilla japonica.

Locality and date of collection: Yoshida, Shizuoka Pref. on 12 Sept. 1981.

No. of specimens: 20 (all fixed in ammonium picrate-glycerin).

Specimens: Holotype and some paratypes deposited in the Meguro Parasitological Museum, M. P. M. Coll. No. 19480 and the other paratypes in the authors' collection.

Description: Body, of medium size, 0.51$0.65 \mathrm{~mm}$ long. Hamuli $46-51$ in total length with inwardly bent root, 13-16 long, base (shaft) 34-38 long and point 25-28 long. Ratio of root to base 2.2-2.8. Ventral bar slightly arcuate, 20-23 $\times 4.5-7$ in size with short lateral processes, 1.5-2 long and membrane 12-17 long, tapering distally with rounded margin. Dorsal bar 18$21 \times 1.5-2$ in size, with lateral spurs near the junction with bullae. Marginal hooks 25-28 in total length; handle 20-23 long and domus (loop) 14-16 long. Hook proper somewhat stout, 5-5.5 long, with strongly curved blade and well developed outer protrusion of base, 5-6 in distal width and 4 in proximal width. Male copulatory organ 11-17 in diameter, cirrus short and tapering distally, 3.5-5 long, guarded by a single row of about $6-8$ minute spines.
Remarks: Gyrodactylus egusai sp. nov. is most similar to G. varicorhini ERGENS et IBRAGIMOV, 1976 in the shape of the opisthohaptoral hard parts, but can be separated from it in considerably smaller hamuli and marginal hook proper. This new species is named in honor of Dr. S. EgusA, emeritus professor of the University of Tokyo.

\section{Gyrodactylus joi sp. nov.}

(Figs. 5-7)

Host and habitat: On the body surface of Anguilla japonica.

Locality and dates of collection: Yoshida, Shizuoka Pref. on 30 June and 03 July, 1981.

No. of specimens: 16 (all fixed in formalin).

Specimens: Holotype and some paratypes deposited in the Meguro Parasitological Museum, M. P. M. Coll. No. 19481 and the other paratypes in the authors' collection.

Description: Body $0.26-0.41 \mathrm{~mm}$ long. Hamuli 47-52 in total length with straight root, 16-21 long, base (shaft) 35-38 long and point 26-28 long. Ratio of root to base 1.8-2.3. Ventral bar well developed, arcuate, $26-28 \times 4-5$ in size with short lateral processes, $1.5-2.5$ long and membrane 22-26 long. The latter tapering posteriorly with increasing thickness, developing lateral outgrowths at posterior end. Dorsal bar $18-26 \times 2$ 3.5 in size with lateral spurs near the junction with bullae. Marginal hooks $24-27$ in total length; handle 18-21 long and domus (loop) 13-15 long. Hook proper 5.5-6 long with less sharply curved blade and broad base, 5-5.5 in distal width and 4 in proximal width. Male copulatory organ 14 24 in diameter, cirrus $6.5-8$ long, curved and surrounded by a single row of about 6-8 spines.

Remarks: Gyrodactylus joi sp. nov. is most related to G. anudarini ERgENs et DulmaA, 1968 in the shape of hamuli and bars, but can easily be distinguished from the latter in the shape of the marginal hook proper. The specific name, $j o i$, is taken from Dr. Y. Jo, Tokushima Prefectural

Figs. 1-4. Gyrodactylus egusai sp. nov. 1: hamuli, bars and marginal hook of holotype, 2: same of paratype, 3: marginal hook proper of holotype, 4: male copulatory organ of paratype. Scale $a$ for Fig. 3 and $b$ for Figs. 1, 2 and 4.

Figs. 5-7. Gyrodactylus joi sp. nov. 5: hamuli, bars and marginal hooks of holotype, 6: marginal hook proper of holotype, 7: male copulatory organ of holotype (left) and of paratype (right). Scale $a$ for Fig. 6 and $b$ for Figs. 5 and 7 . 

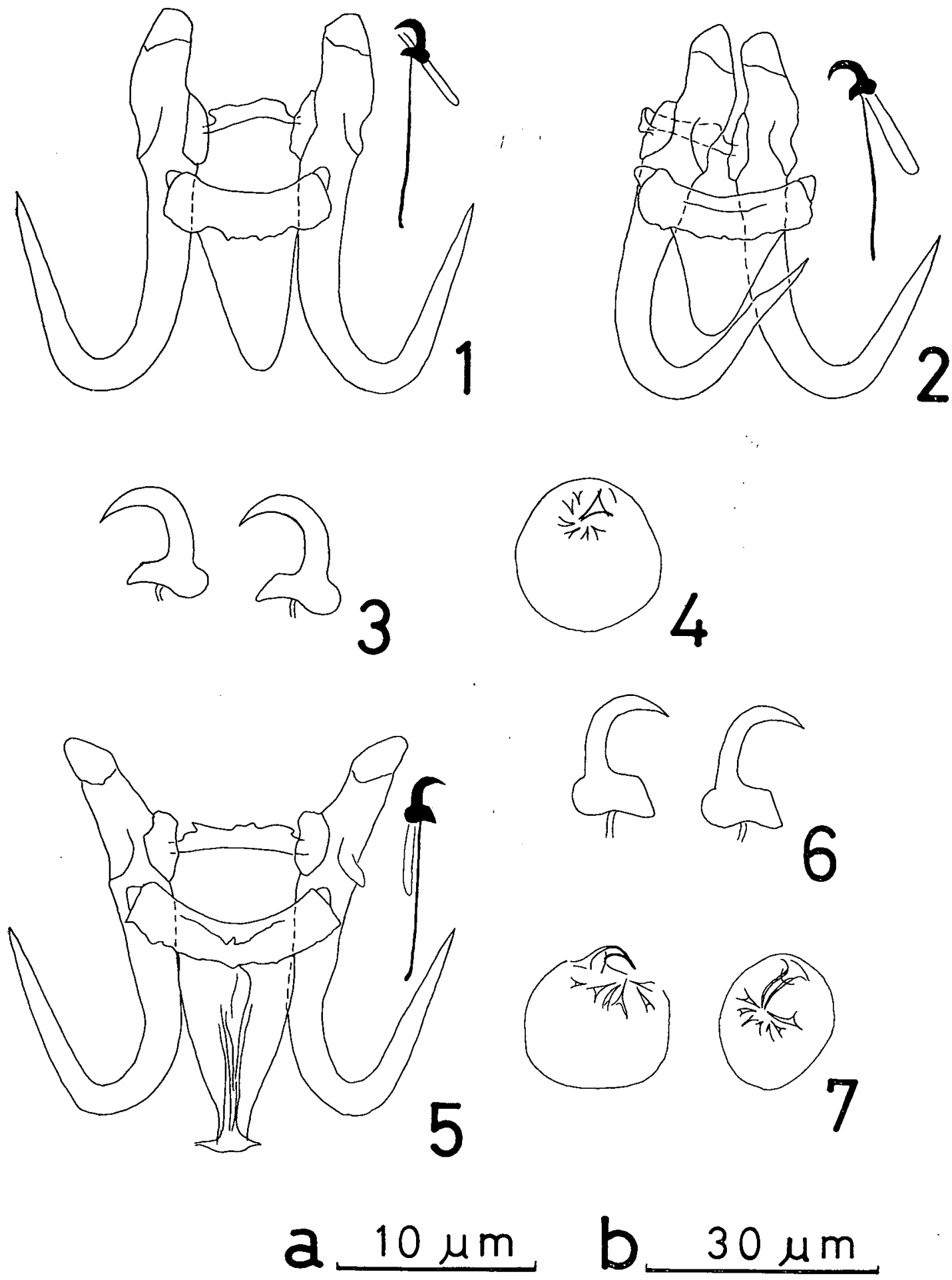

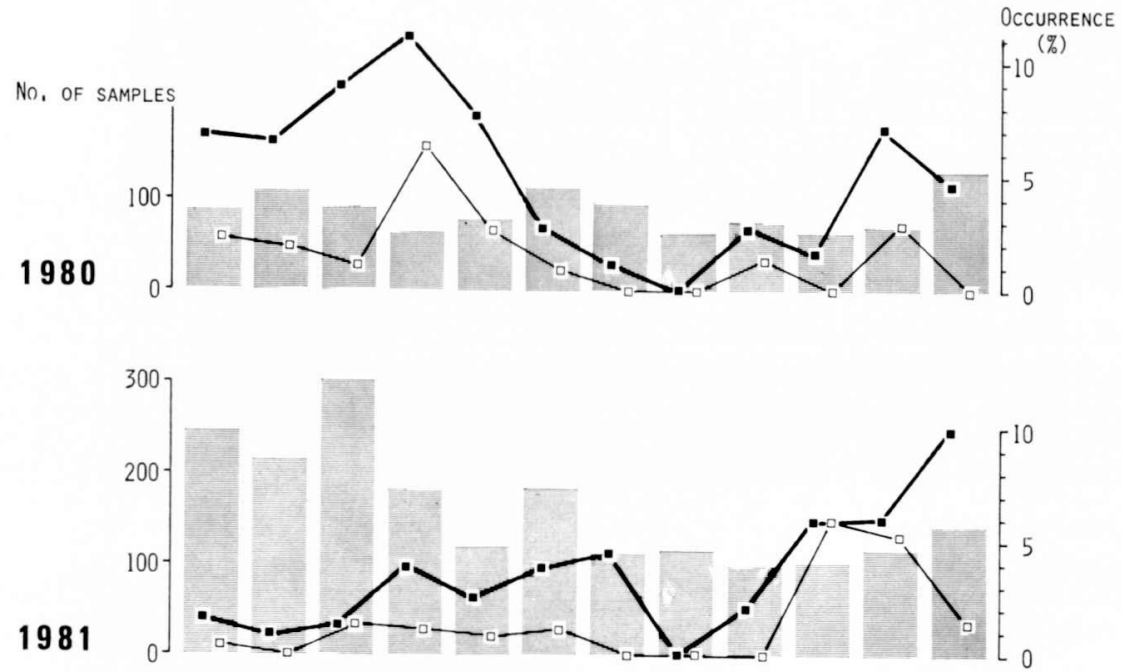

1982

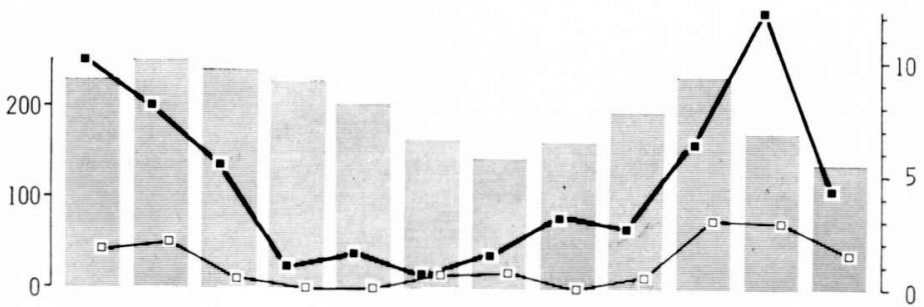

1983

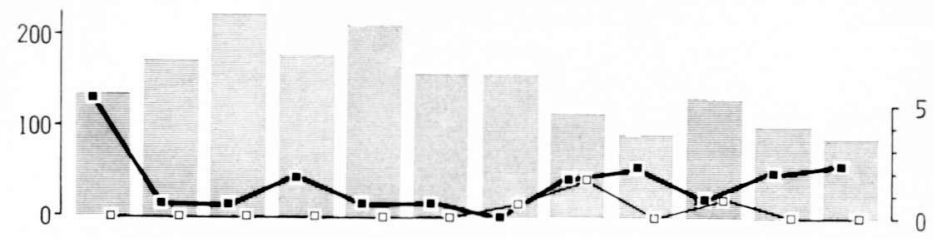

1984
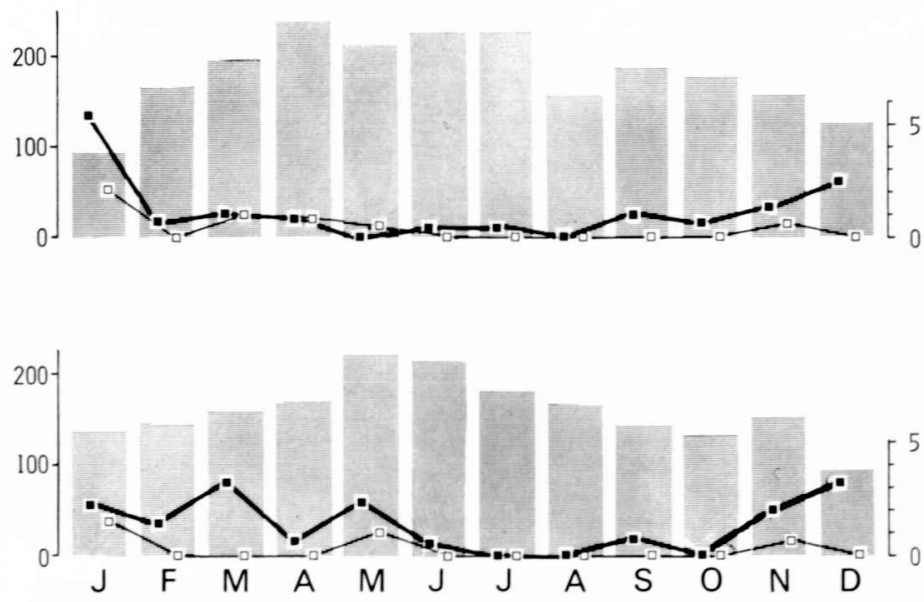


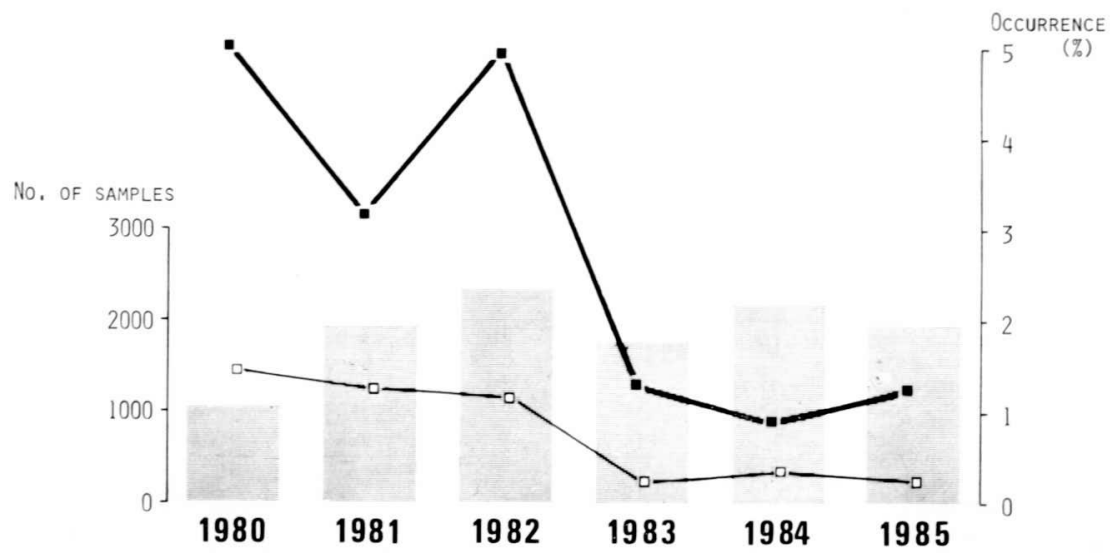

Fig. 9. Long term changes in the occurrence of Gyrodactylus of eel in greenhouse ponds in 19801985. Symbols as in Fig. 8.

Fisheries Experimental Station.

Occurrence of gyrodactylids in greenhouse culture in $1980-1985$

An examination of some preserved Gyrodactylus specimens has revealed that out of seven samples of scrapings of the body surface of the host, five were infected with G. egusai sp. nov., one with $G$. joi sp. nov. and one with both species, while all gills were infected with G. nipponensis. Thus, it is supposed that Gyrodactylus on the gill filaments represented G. nipponenisis. On the other hand, Gyrodactylus on the body surface included the two new species.

Of total of 11, 152 samples of eel in greenhouse ponds, Gyrodactylus were found from the body surface of 296 samples $(2.65 \%)$ and from the gill filaments of 83 samples $(0.74 \%)$.

The record is arranged on a monthly basis (Fig. 8). Gyrodactylus on the body surface was found from 0 to $12.2 \%$ of the samples, while gill Gyrodactylus ( $=G$. nipponensis) from 0 to $6.3 \%$; the latter seldom outnumbered the former in each month. With regard to seasonal fluctuations, Gyrodactylus both on the body surface and on the gills tended to be less abundant in summer than in the other seasons. Changes in the occurrence with year (Fig. 9) have shown that gyrodactylids on both sites of the host were much more frequently ob- served in 1980-1982 than in 1983-1985.

\section{Discussion}

Gyrodactylus egusai sp. nov. and G. joi sp. nov. are the second and third species of Gyrodactylus of eel, Anguilla japonica, following G. nipponesis on gill filaments. G. anguillae and G. nipponensis have been known from the gill filaments of European eel, Anguilla anguilla, introduced to Japan for culture (OGawa and Egusa, 1980).

All the eel examined in the present study had been cultured in greenhouse ponds, where water temperature was usually about $25^{\circ} \mathrm{C}$ or above. In summer, it rose as high as $30^{\circ} \mathrm{C}$. The lower frequency in the occurrence in summer was possibly caused by the higher water temperature.

It is interesting to note that Gyrodactylus on the body surface and gill filaments has been less frequently found since 1983 (Fig. 9). An environmental change, if any, is most likely to be the cause, and the quality of pond water has been one of the most marked changes in recent years. All greenhouses are equipped with boilers to keep pond water warm in cold seasons. Turnover rate of water in greenhouse ponds has considerably decreased and the water quality has become worsened beacuse of a great rise in the price of heavy oil for boilers. This may be responsible for the recent decrease in Gyrodactylus populations in eel ponds

Fig. 8. Monthly fluctuations in the occurrence of Gyrodactylus of eel in greehnouse ponds in 19801985. Vertical bars: no. of samples examined, $\mathbf{n}$ : occurrence of Gyrodactylus on the body surface, $\square$ : occurrence of Gyrodactylus on the gill filaments. 
there.

In Yoshida area, eel is also cultured in outdoor ponds, especially in summer. 464 samples of eel in outdoor ponds had been examined for parasites during the same period. No infection with Gyrodactylus had been found on the gill filaments, and seven cases of infection on the body surface had been recorded. Because of much smaller number of samples, no tentency in the occurrence was clear and it also seems difficult to compare the result with the data in greenhouse ponds.

\section{Acknowledgement}

The authors would like to thank Mr. K. Nishio and other staff of Laboratory of Maruhai-Yoshida Eel Farmers' Cooperative Association, Haibara, Shizuoka Pref. for generous co-operation and encouragement throughout the study.

\section{References}

Ergens, R. and A. DulmaA (1968): Monogenoidea in Cobitis taenia sibirica from Mongolia. Folia Parasitol., 15, 317-321.

ERgens, R. and S. Ibragimov, (1976): Three new species of Gyrodactylus (Monogenoidea) from Varicorhinus capsoeta gracilis (KEYSERLING) from the River Lenkoranka. Folia Parasitol., 23, 179182.

Ogawa, K. and S. Egusa (1978): Seven species of Gyrodactylus (Monogenea: Gyrodactylidae) from Plecoglossus altivelis (Plecoglossidae), Cyprinus carpio (Cyprinidae) and Anguilla spp. (Anguillidae). Bull. Japan. Soc. Sci. Fish., 44, 613-618.

OGAWA, K. and S. EgusA (1980): Gyrodactylus infestations of cultured eels (Anguilla japonica and $A$. anguilla) in Japan. Fish Pathol., 15, 95-99. (in Japanese). 